\title{
La huella de Lope de Vega en Cómo se vengan los nobles, de Moreto: continuidades y disidencias
}

\author{
Lope de Vega's Footprint in \\ Cómo se vengan los nobles, by Moreto: \\ Continuity and Dissent
}

Javier Castrillo Alaguero

Universidad de Burgos

Calle Paseo de los Comendadores, s/n. Burgos, 09001 jcalaguero@ubu.es

Orcid ID 0000-0003-3238-3774

Resumen: Ruth Lee Kennedy, en The Dramatic Art of Moreto (1932), señaló once comedias de Moreto escritas a partir de obras de Lope. Sin embargo, no todos estos casos parecen ceñirse a la auténtica autoría de Lope y a la correspondiente versión de Moreto. Esta investigación, después de exponer una serie de cuestiones teóricas acerca de los conceptos de reescritura/refundición/intertextualidad, pretende abordar uno de estos pares de reescritura: El testimonio vengado, de Lope, y Cómo se vengan los nobles, atribuida a Moreto, ahondando, entre otros aspectos, en las similitudes y divergencias existentes entre ambas obras en lo que concierne al argumento, a los personajes o al espacio y al tiempo donde se desarrolla la acción.

Palabras clave: Agustín Moreto. Lope de Vega. Reescritura. Refundición. Intertextualidad.
Abstract: Ruth Lee Kennedy, in her The Dramatic Art of Moreto (1932), pointed out eleven comedies by Moreto that were based on previous plays by Lope. However, not all of those cases stick to the authentic authorship of Lope and the corresponding version of Moreto. This research, after present some theoretical questions about concepts like rewriting/recasting/intertextuality, aims to address one of these rewriting pairs: El testimonio vengado, by Lope, and Cómo se vengan los nobles, attributed to Moreto, deepening, among other aspects, in the similarities and divergences present between both works in regards to the plot, the characters or the space and the time where the action takes place.

Keywords: Agustín Moreto. Lope de Vega. Rewriting. Recasting. Intertextuality. 
INTRODUCCIÓN

— n las últimas décadas han sido muchos los acercamientos críticos que se han producido en torno al fenómeno de la reescritura en el teatro del Siglo de Oro. Sin embargo, todavía no se ha realizado un trabajo de conjunto que aglutine las investigaciones ya realizadas y trate de fijar una metodología de análisis que sirva como punto de partida para estudios futuros.

En 1998, con motivo de la celebración en la Casa de Velázquez de Madrid del seminario Siglo de Oro y reescritura. I: Teatro, cuyos trabajos se recogieron posteriormente en el monográfico número 72 de la revista Criticón, José María Ruano de la Haza propuso cinco técnicas o métodos diferentes dentro del mecanismo de la reescritura. Entiende por refundición "la práctica de componer una comedia nueva basándose en elementos -temas, situaciones, personajes- de otra anterior" (35); la reelaboración "pule, perfecciona, afina y modifica un texto teatral para crear una nueva versión, y puede ser llevada a cabo por el propio dramaturgo" (35); por reconstrucción alude "al intento de recobrar parcial o totalmente un texto teatral perdido con el propósito de recuperar la versión original" (35); con adaptación se refiere "a la práctica de adecuar un texto teatral, eliminando personajes o escenas que se consideran superfluos, o introduciendo nuevos pasajes y personajes, para producir una versión representable en un lugar escénico específico o por una compañía determinada" (36); por último, la reutilización "consiste en el aprovechamiento de una escena o pasaje textual en diferentes piezas teatrales" (36).

La utilidad e impacto de la taxonomía de Ruano se cifra en que dichas técnicas o métodos han sido citados a posteriori en otros trabajos por un sinfín de críticos como, por ejemplo, Fernando Rodríguez-Gallego, Francisco Sáez Raposo, Alejandra Ulla Lorenzo, Marcella Trambaioli o Zaida Vila Carneiro, entre otros muchos.

No obstante, existen también otras propuestas conceptuales que difieren parcialmente de las anteriores como las de Marc Vitse, Anne Cayuela, José Antonio Pérez Bowie o Santiago Fernández Mosquera, quien afirma, por ejemplo, que "detrás de toda reescritura se esconde un proceso intertextual, pero no toda intertextualidad es reescritura" (24). Por tanto, directamente relacionada con este concepto de reescritura está también la idea de intertextualidad. Aunque son muchos los planteamientos críticos existentes sobre este tema, siendo pieza angular el realizado por Gérard Genette, destaca la expli- 
cación aportada en 1992 por Maria Grazia Profeti, ya que postula que si "se utiliza el concepto de intertexto, la polémica [...] pierde todo su interés, ya que se admite tranquilamente la posibilidad de relación de una obra con las anteriores, con las cuales establece un enlace dinámico" (110).

Asunto diferente serían los casos de plagio literales, pero estos son escasos en la obra moretiana, donde lo más interesante son los fenómenos de reescritura, "donde los materiales de un texto se insertan en otro texto, es decir un con-texto diferente del original, lo que exige su reelaboración" (Vaccari 88).

En definitiva, a pesar de que en el caso del teatro áureo tanto la idea de reescritura como la de intertextualidad tienen sus raíces en el concepto clásico de imitatio -las obras escritas pertenecen a la comunidad y pueden ser utilizadas por ella-, ambos términos se sitúan en dos niveles distintos. Por ello, es necesario diferenciar en qué grado el refundidor ha realizado un proceso consciente y voluntario de reutilización de materiales previos -ya sean propios o ajenos- para poder tildarlo con un vocablo (reescritura) u otro (intertextualidad).

Ruth Lee Kennedy, en The Dramatic Art of Moreto, apuntó once comedias de Moreto escritas a partir de obras de Lope. Sin embargo, de estos once casos propuestos por la hispanista estadounidense, los que realmente parecen ceñirse a la auténtica autoría de Lope y a la correspondiente versión de Moreto son, según Elena Di Pinto, los siguientes: El testimonio vengado de Lope y Cómo se vengan los nobles de Moreto; ¿De cuándo acá nos vino? de Lope y De fuera vendrá de Moreto; El caballero del sacramento de Lope y El Eneas de Dios de Moreto; Mirad a quién alabáis de Lope y Lo que puede la aprehensión de Moreto; El despertar a quien duerme de Lope y La misma conciencia acusa de Moreto; y, por último, El mayor imposible de Lope y No puede ser de Moreto. Como afirma Elena Di Pinto, "los otros cinco casos propuestos por la estudiosa están repletos de problemas, pues ni la autoría del drama de origen es de Lope ni la versión es solo de Moreto, sino que se trata de comedias escritas en colaboración, práctica muy habitual por aquel entonces y que últimamente se está estudiando más a fondo" (109). Los últimos dos pares de comedias citados ya fueron estudiados y publicados en 2011 y 2010, respectivamente, por Elena Di Pinto. De acuerdo con este estado de la cuestión, este artículo pretende continuar el análisis de estas reescrituras moretianas realizadas a partir de fuentes lopescas centrándose en una de ellas: El testimonio vengado, de Lope, y Cómo se vengan los nobles, atribuida a Moreto, con el fin de exponer las similitudes y di- 
vergencias más destacadas que se pueden apreciar entre la obra de Agustín Moreto y la comedia previa en lo que respecta a la caracterización de los personajes, al título de la obra, al espacio y tiempo donde se desarrolla la acción, al lenguaje y estilo empleados por ambos dramaturgos y, por último, a diversos aspectos formales.

El testimonio vengado es una de las comedias que figuran en la lista de la primera edición de El peregrino en su patria, novela bizantina lopesca protagonizada por personajes de comedia que salió de las prensas en 1604 con aprobación de 1603. No obstante, la editio princeps de esta obra es el texto de la Primera parte de comedias (1604) de Lope de Vega. En su memorable estudio de la versificación de las comedias de Lope, Morley y Bruerton (259) no acaban de precisar la cronología de esta obra, pero la sitúan entre 1596 y 1603, aunque la incluyen en un grupo de piezas que probablemente no fuesen posteriores a 1598. A través del Diccionario biográfico de actores del teatro clásico español podemos saber que Mateo de Salcedo vendió esta y otras comedias al autor Andrés de Heredia en 1601 (López Martínez 69-70).

De la popularidad de esta comedia nos dio testimonio en 1614 el encubierto autor del Quijote de Avellaneda, en el capítulo XXVII, donde describe su representación en una venta:

Comenzaron a ensayar la grave comedia de El testimonio vengado, del insigne Lope de Vega Carpio, en la cual un hijo levanta un testimonio a la Reina, su madre, en ausencia del Rey, de que comete adulterio con cierto criado, instigado del demonio y agraviado de que le negase un caballo cordobés en cierta ocasión de su gusto, guardando en negarle el orden expreso que el Rey, su esposo, le había dado. (449)

Por lo tanto, en fechas muy posteriores a la composición de la comedia, esta era todavía recordada y, como en estas líneas se sugiere, la representaba alguna compañía de teatro. Constituye, pues, un indicio del favor y fama de los que gozaría El testimonio vengado años después, dado que, dejando a un lado los posibles juicios sobre los méritos y valores artísticos de la comedia, se verá que el asunto que dramatiza en ella Lope se mantenía en plena vigencia a través de enconados debates de tipo nacionalista y reivindicativo que por esos años recobraban una vitalidad perdida.

Como indica Menéndez Pelayo (316), Lope de Vega tomó el argumento de esta comedia de la Crónica general, que, en este, como en otros muchos capítulos, no hizo más que traducir al arzobispo de Toledo, don Rodrigo Ji- 
ménez de Rada. Este episodio había suscitado en la época diversas polémicas, dado que la historia, considerada fabulosa por diversos autores, servía para explicar las oscuras circunstancias que envolvieron el testamento de don Sancho el Mayor o, dicho de otra manera, valía para justificar por qué don García, hijo primogénito de Sancho de Navarra y doña Mayor, no sucedió a su padre en los estados de Castilla, y por qué al hijo natural, don Ramiro, se le adjudicó el reino de Aragón. Las distintas versiones de los hechos recogidas en las crónicas medievales, nada concluyentes al respecto y, por lo común, tendenciosas en su enfoque, habían dejado la discusión en un punto muerto que se agravaba con la carencia documental sobre esos años. Por lo tanto, no cabe duda de que todas estas controversias forman parte del importante trasfondo sobre el que Lope trabajó en la elaboración de su comedia, ni de que dichas desavenencias avivaron el interés y la oportunidad de los hechos dramatizados, así como su amplia recepción por parte del público y la segura fama de la obra.

En lo que respecta a Cómo se vengan los nobles, ejemplo de refundición según la terminología de Ruano de la Haza, fue publicada por primera vez 64 años después de la obra lopesca, en la parte 29 de Comedias nuevas escogidas (1668) y, posteriormente, en la Verdadera Tercera Parte de las comedias de Don Agustín Moreto (1676), uno de los cuatro volúmenes facticios de la Tercera parte de las obras de Moreto que aparecieron en los siglos XVII y XVIII. No obstante, poco se sabe de esta Tercera parte, ya que, al igual que la Segunda, editadas en 1681 y 1676, respectivamente, fue publicada de forma póstuma y, además, contiene numerosas atribuciones que no son suyas.

Lo que sí que se puede afirmar es que esta comedia palatina se inserta dentro de la segunda etapa de producción del dramaturgo madrileño, la cual transcurre entre 1655 y 1669, año de su fallecimiento. En esta segunda fase Moreto compuso veinte obras, de las cuales seis pasaron a la Segunda parte de comedias de 1676 (Lobato 63). En este periodo el cambio más notable con respecto a la primera (1639-1654) se dio en la disminución de su producción de obras mancomunadas con otros autores, pues en esta etapa solo se data la que hizo con Matos Fragoso titulada San Froilán, de atribución dudosa. Este cambio tan notable pudo deberse tanto a su alejamiento espacial de Madrid, ya que Moreto ejercía en ese momento sus tareas sacerdotales en Toledo, como a su distanciamiento de la propia corte de los Austrias, pues la representación particular en palacio era uno de los destinos más habituales de sus obras. En definitiva, el cambio en sus circunstancias vitales, 
derivado de su ordenación sacerdotal y sus nuevas responsabilidades en Toledo, se manifestó en la segunda etapa en un cierto aislamiento que complicó la composición de nuevas obras en colaboración con otros dramaturgos, la disminución de sus comedias en solitario y el incremento de sus piezas cómicas breves.

Por último, Cómo se vengan los nobles se mantuvo en el repertorio teatral de la época hasta 1842, año en el que José Zorrilla renovó el argumento de dicha comedia en uno de los mejores dramas históricos, El caballo del rey D. Sancho (Menéndez Pelayo 327). A pesar de no conocer la pieza de Lope, parece ser que sí aprovechó la de Moreto para darle más interés a la trama, mostrando gran brillantez y frescura en la ejecución.

\section{Similitudes y DIVERGENCIAS ENTRE LA OBRA DE MORETO Y SU FUENTE}

En lo que respecta al argumento general de las dos comedias, las líneas principales coinciden. En ambas el desencadenante de la acción es la falsa acusación de adulterio por parte de los infantes don García, don Fernando y don Gonzalo contra su madre, la Reina doña Mayor, y el caballerizo real Pedro Sesé, motivada por el impedimento de estos a que monten el caballo blanco andaluz de su padre, el rey don Sancho. Del mismo modo, en las dos obras será Ramiro, el hijo ilegítimo, el encargado de defender la inocencia de su madrastra venciendo en el campo de batalla al primogénito del rey, don García. La única gran diferencia la encontramos en el personaje encargado de desvelar a Ramiro sus nobles orígenes, ya que, mientras en El testimonio vengado es Belisardo, su ayo, en la obra de Moreto es la propia doña Mayor, lo cual carga de fuerza dramática el acontecimiento.

En lo concerniente al título de la comedia, Lope realza el motivo que desencadena toda la acción de la obra -el falso testimonio de los nobles-, mientras que Moreto cambia el punto de vista, poniendo el foco de atención en las personas que llevan a cabo este fraudulento testimonio, en este caso, los infantes don García, don Fernando y don Gonzalo, lo que contribuye a incrementar la fuerza de la acusación.

Por otro lado, Moreto reduce notablemente el número de personajes, ya que se pasa de 17 a 13. Sin embargo, respeta con bastante fidelidad el nombre de los protagonistas, ya que únicamente encontramos un cambio en el personaje encargado de formar a Ramiro en la aldea: Belisardo en la obra de Lope, Fortún en la de Moreto. Además, Moreto otorga más protagonismo a la figu- 
ra del gracioso, llamado Buscón en su obra, ya que lo dota de más comicidad y le hace aparecer en escena en un mayor número de ocasiones.

Del mismo modo, directamente relacionado con la reducción de las dramatis personae, se puede apreciar en Cómo se vengan los nobles una presencia más prolongada de los personajes en escena, lo que produce la existencia de parlamentos más largos y complejos, y ralentiza el dinamismo de la acción. Esto se evidencia en el pasaje en el que don García, vencido por Ramiro, reconoce su falso testimonio:

El testimonio vengado, de Lope de Vega Cómo se vengan los nobles, de Agustín Moreto

DON GARCía ¡Basta, poderoso hermano; basta, don Ramiro fuerte; basta, no me des la muerte, detén la espada y la mano: confieso que soy vencido!

RAMiro ¡Más es menester confieses!

DON GARCÍA Aunque la muerte me dieses, lo tengo bien merecido. Confieso que levanté lo que de vergüenza callo, porque no me dio un caballo la Reina, a quien afrenté. ¡A Dios, a ella y al Rey perdón pido!

(vv. 2521-34)

DON GARCía Tened

las armas, y suspended el que yo pierda la vida. El negarme Pedro Sesé y la reina, mi señora, el caballo, ;oh, rey invicto, estando tú en Zaragoza!, cerró puertas al discurso, que el enojo en la edad moza es tempestad resistida, que rompe con cuanto topa, y ocasionó que intentase una acción tan afrentosa, una traición contra ti, y contra mí una deshonra. La reina es luz de Navarra, es pura y cándida aurora, excepción de toda eclipse, fénix única española. Pedro Sesé en la lealtad merece que se anteponga a cuantos inmortalizan los bronces y las historias. Los dos infantes creyeron persuasiones marañosas de un hermano que veneran, sucesor de tu corona.

A tus pies, padre y señor, aguardo el castigo ahora, mas donde está la venganza los demás castigos sobran. (vv. 2452-82)

Por otra parte, tanto en Cómo se vengan los nobles como en El testimonio vengado la residencia real parece ubicarse en Nájera. Sin embargo, en la obra de 
Lope, donde la alternancia de espacios es mucho mayor, hay bastantes más pasajes desarrollados en palacio que en la de Moreto. Un ejemplo de ello se puede apreciar en la primera jornada, ya que mientras que en la obra de Moreto toda la acción transcurre en la aldea, en la de Lope observamos la variación entre el medio urbano y el medio rural.

Esta concentración de espacios se observa también en el empleo del tiempo. Lope de Vega hace transcurrir un año entre la acusación de adulterio de la Reina y el día del juicio en el que Ramiro sale a combatir en defensa de su honor. Este plazo ni estaba en la leyenda ni parece ser necesario para dar ocasión al conocimiento entre doña Mayor y su hijastro, que podía haber sido preparado más ingeniosamente desde el primer acto, tal como efectúa Moreto en su obra. No obstante, este drama pertenece a la primera manera de componer de Lope, donde aún su técnica no estaba demasiado depurada. Por lo tanto, dado que Moreto reduce el plazo del desafío a tan solo un mes, se puede afirmar que en Cómo se vengan los nobles se produce una concentración temporal que sintetiza la estructura dramática, lo cual permite que la trama sea más fácil de seguir por parte del espectador.

En esta línea de la economía dramática, otro cambio llamativo que se puede apreciar en la obra de Moreto con respecto a la de Lope es la simplificación del enredo. Este hecho se evidencia no tanto en el número de versos de las obras (2 554 de Cómo se vengan los nobles frente a 2636 de El testimonio vengado), sino en la elisión, por ejemplo, del argumento secundario. Mientras que en El testimonio vengado presenciamos una aventura amorosa entre dos pastores, Celia y Marcelo, que corre paralela al desarrollo de la trama principal y termina en boda, en Cómo se vengan los nobles no se aprecia prácticamente ningún desvío de la misma, lo cual permite focalizar mucho más la intriga central. Como afirma Buscón, el gracioso de la obra moretiana, al final de la pieza: "Esto se ha hecho sin boda / que es novedad de comedia" (vv. 2550-51).

Novedad significativa también es que, mientras en El testimonio vengado el rey don Sancho es consciente de que tiene un hijo natural oculto en la aldea, en Cómo se vengan los nobles este hecho es desconocido por el monarca cuando se inicia la pieza teatral. Del mismo modo, a pesar de la simplificación de la materia dramática, Moreto respeta la repartición de la misma en tres actos, aunque con ciertas diferencias. Por ejemplo, en El testimonio vengado la acusación de adulterio por parte de los infantes se produce al final de la primera jornada, mientras que en Cómo se vengan los nobles esta no se produce hasta el final del segundo acto. Es evidente que, con estos detalles, Moreto con- 
sigue aumentar el suspense dentro de su comedia y concentrar la tensión dramática en el acto final.

En lo respectivo al uso de las acotaciones se produce una amplificatio, no tanto de número (61 en la obra de Lope, 71 en la de Moreto), sino de extensión. Es decir, se aprecia en algunos casos una mayor descripción por parte de Cómo se vengan los nobles en la caracterización de los personajes, hecho crucial para su posterior puesta en escena, como evidencian los siguientes ejemplos: ${ }^{1}$

El testimonio vengado, de Lope de Vega Cómo se vengan los nobles, de Agustín Moreto

Vanse, y entran Belisardo, pastor, y el Conde. (vv. 717-18)

Vanse, y sale el rey con una gabardina de grana, y soldados, y luego, por otra parte, Ramiro y Buscón abrazados, medio desnudos. (vv. 881-82)

Vanse y sale el Rey de camino, y los tres hermanos. (vv. 830-31)

Tocan cajas destempladas, y salen marchando los tres infantes con luto.

(vv. 1812-13)

Vase, y sale el Rey, y don Luis.

Música triste; se descubra un tribunal, de luto, y en él el rey y dos jueces a los lados, y a otra parte, en un tribunal más pequeño, la reina de luto, con un tafetán por los ojos.

(vv. 2362-63)

También en las esticomitias se observan diferencias, ya que mientras en El testimonio vengado no se encuentra ninguna, en Cómo se vengan los nobles se suceden en repetidas ocasiones e incluso se da muestras de su uso por medio de las acotaciones: "Han estado la reina y los infantes hablando en aparte" (vv. 762-63), logrando Moreto a través de ellas una mayor conexión con el público.

En lo referente al lenguaje, a pesar de mejorar la trama evitando algunas de las incongruencias presentes en la obra de Lope -como, por ejemplo, el tiempo que transcurre entre la acusación de adulterio y el día del juicio-, Moreto reescribe la obra lopesca con versos menos poéticos, menos líricos, a los cuales el componente épico llega de forma muy tenue. Un ejemplo de ello lo apreciamos en la escena de adopción de Ramiro por parte de doña Mayor, la cual, presentada de forma muy solemne en El testimonio vengado, queda reducida en Cómo se vengan los nobles a unos escuetos versos:

1 En efecto, a menudo las acotaciones proceden de las compañías y responden a las necesidades escénicas de la obra. No se descarta que así sea en este caso. 


\begin{tabular}{|c|c|c|c|}
\hline \multicolumn{2}{|c|}{ El testimonio vengado, de Lope de Vega } & \multicolumn{2}{|c|}{ Cómo se vengan los nobles, de Agustín Moreto } \\
\hline REINA & $\begin{array}{l}\text { ¡Dame esos pies vencedores, } \\
\text { don Ramiro, que tú eres mi hijo! }\end{array}$ & \multirow[t]{12}{*}{ REINA } & $\begin{array}{l}\text { Tú solo, ¡oh, joven del cielo! } \\
\text { eres mi hijo. A ti te tocan }\end{array}$ \\
\hline RAMIRO & Tu esclavo soy. & & mis herencias, mis estados, \\
\hline REINA & Y, a ti, mi señor, te doy & & mi sucesión y corona. \\
\hline & mis brazos, pues que los quieres. & & Más perfecto sale siempre \\
\hline & Y, pues sentencia me pides, & & el que la elección adopta \\
\hline & $\begin{array}{l}\text { a vos, García, desheredo, } \\
\text { si con tu licencia puedo. }\end{array}$ & & $\begin{array}{l}\text { que el que la naturaleza, } \\
\text { tantas veces defectuosa. }\end{array}$ \\
\hline REY & Tu agravio y mi afrenta mides. & & Perseguida, me amparaste, \\
\hline REINA & Y porque afrentado vivas & & y mis hijos, ¡oh, qué impropia \\
\hline & de tu infamia en cualquier parte, & & acción de naturaleza!, \\
\hline & aunque pudiera matarte, & & lutos a mi afrenta cortan. \\
\hline & $\begin{array}{l}\text { yo te condeno a que vivas; } \\
\text { vive, } y \text { viva tu pecado }\end{array}$ & & $\begin{array}{l}\text { Luego, tú solo mereces } \\
\text { que mi Castilla te ponga }\end{array}$ \\
\hline & $\begin{array}{l}\text { siempre en tu rostro y contigo, } \\
\text { porque no hay mayor castigo }\end{array}$ & & $\begin{array}{l}\text { de sus condes la diadema. } \\
\text { ¡Feliz, si dueño te goza! }\end{array}$ \\
\hline
\end{tabular}
que dar vida a un afrentado. Doyle a Castilla, que es mía, con el reino de León, a Ramiro.

MARCELO ¡Brava cosa!

REY Y yo Aragón.

¡Rey es de todo este día!

REINA Si acaso España repara en que yo no le parí, hoy ha de nacer de mí como si yo lo engendrara. Hijo te tengo de hacer de la manera que puedo, $\mathrm{y}$ al traidor que desheredo quito la sangre y el ser. Entra debajo el brïal, si en las entrañas no puedes, porque legítimo heredes lo que pierdes natural; y si, como dicen, hace la imaginación efecto, yo te engendro en mi concepto, y, así, agora al mundo nace. Tu madre soy; sal, que llega el parto, aunque sin dolor, que, por parir tu valor, hasta el dolor se me niega. Yo te parí claramente, tu madre soy...

Marcelo ¡Brava cosa! REINA Y, a quien dijere otra cosa, le puedes decir que miente. (vv. 2544-88) 
Del mismo modo, el incremento de los elementos cómicos en la obra moretiana conlleva la utilización de un léxico más cotidiano, hasta el punto de que, en algunos casos, como se puede apreciar en las intervenciones de Buscón, el gracioso de la obra, resulta un tanto vulgar. Como se ha afirmado anteriormente, en Cómo se vengan los nobles Buscón es el clásico gracioso que acompaña a su señor comentando grotescamente los acontecimientos y llevando, de este modo, toda la carga cómica de la obra. Por el contrario, en El testimonio vengado no apreciamos un personaje que desempeñe esta función de manera destacada, ya que únicamente se encuentran algunas escenas jocosas en las intervenciones celosas de Marcelo, cuyo lenguaje no es propio de un pastor. Por lo tanto, el componente cómico tiene en la obra lopesca mucho menos espacio y, como consecuencia, menor importancia en la economía dramática general, tal como se observa en las escenas amorosas del siguiente ejemplo:

El testimonio vengado, de Lope de Vega

Marcelo Ocupad este lugar, dueño del alma que tengo, aunque ya resuelto vengo que el alma habéis de ocupar.

Celia Pues llegó, Marcelo, el día en que cumplió mi esperanza el deseo que tenía, la que tanto bien alcanza muy justamente porfía.

Marcelo El día que dio el Imperio de Roma Alejandro en pago del dichoso cautiverio, y Dido la gran Cartago en afrenta y vituperio, cuando Aníbal venció en Canas, y Atila vio las romanas plazas de sangre cubiertas y entró Scipión por sus puertas con banderas africanas no igualan a aqueste día claro, alegre y venturoso en que gozo, ¡ah Celia mía!, el triunfo de ser tu esposo, que es lo que al cielo pedía. (vv. 2236-59)
Cómo se vengan los nobles, de Agustín Moreto

Sol ¡Ah, Buscón! ¡Tú a ver el mundo te vas y acá nos quedamos! Mas di, ¿para que me acuerde de ti no me dejas algo?

Buscón ¿Qué?

SOL Una prenda de tu amor.

Buscón No la tengo, Dios loado; pero yo os dejo mi burra por vuestra. Empero, es el caso que es de señor. Si él quisiere, tendréis con ella cuidado.

Sol ¡Tonto! No es eso.

Buscón Pues, ¿cómo tiene de ser?

Sol Mira. Cuando se despide de su dama uno que está enamorado, diz que le da una cadena, un anillo o un retrato, para que tenga memoria.

Buscón Si eso es, ya estoy pensando qué daros. Poneos al cuello esta cadena, que al cabo también un anillo tiene. Échala al cuello una cincha 


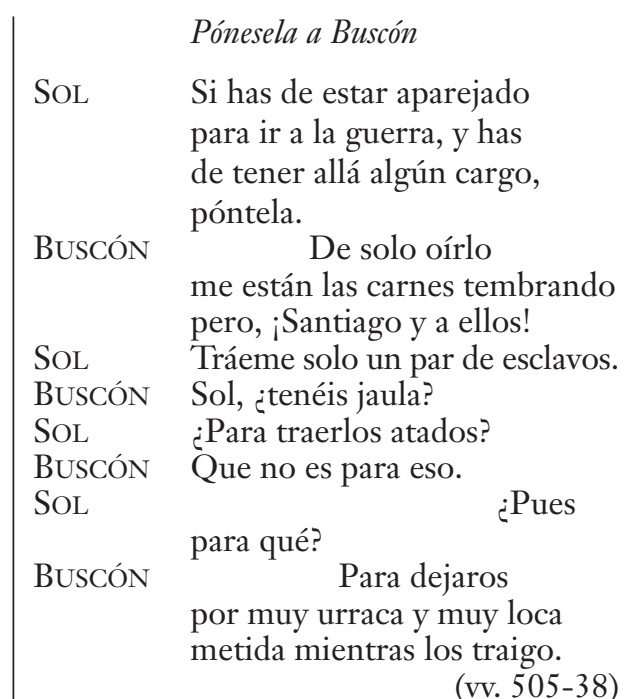

Por último, encontramos en ambas obras pasajes con versos muy similares, los cuales sirven a Moreto como punto de arranque para construir su comedia, como, por ejemplo, cuando el Rey encarga a la Reina doña Mayor que nadie suba a su caballo blanco, ya que lo tiene en gran estima:

\begin{tabular}{|c|c|c|c|}
\hline \multicolumn{2}{|c|}{ El testimonio vengado, de Lope de Vega } & \multicolumn{2}{|c|}{ Cómo se vengan los nobles, de Agustín Moreto } \\
\hline REY & $\begin{array}{l}\text { De cosas de mi regalo } \\
\text { no hay, señora, qué miréis, } \\
\text { sino es una que sabéis } \\
\text { que al mayor que tengo igualo: } \\
\text { aquel caballo famoso } \\
\text { que me dio el rey cordobés } \\
\text { todo mi regalo es, } \\
\text { porque es en estremo hermoso; }\end{array}$ & $\begin{array}{l}\text { REINA } \\
\text { REY }\end{array}$ & $\begin{array}{l}\text { Nadie se pondrá en él. Perded cuidado. } \\
\text { Es en esto mi gusto tan prolijo } \\
\text { que lo reservo aun de mi propio hijo. } \\
\text { Vuestra alteza lo mande así, y lo advierta } \\
\text { a los infantes si quisiere alguno } \\
\text { lo contrario intentar, estando cierta } \\
\text { que será para mí muy importuno } \\
\text { cualquiera que deste orden se divierta. }\end{array}$ \\
\hline
\end{tabular}
pídoos que no suba en él nadie, aunque mi hijo sea. (vv. 293-302)

(vv. 726-33)

Y pueden también encontrarse fragmentos diferentes formalmente, pero con temática afín, como cuando Ramiro le declara a la Reina que irá a la Corte para defender su inocencia: 


\begin{tabular}{r|c} 
El testimonio vengado, de Lope de Vega & Cómo se vengan los nobles, de Agustín Moreto \\
\hline RAMIRo Iré a la corte, donde, armado en campo, & RAMIRO Y por si también ahora \\
haré que se desdiga mi enemigo, & permite el cielo que de una \\
que, si una vez en él la planta estampo, & desdicha nazca un abono, \\
verás cómo hago allá lo que aquí digo. & como tal vez acostumbra, \\
Ni en julio el sol ni de la nieve el ampo & yo juro por esta espada, \\
en el hebrero bastarán conmigo & que de reliquias purpúreas \\
a quitarme las armas ni las astas, & y de humor rojo vertido \\
sin cubrir de laurel tus sienes castas. & del alarbe aún no está enjuta, \\
(vv. 1802-09) & que no he de creer quién soy \\
& hasta que en batalla dura, \\
de tanta infamia te vengue & y tanto traidor destruya. \\
(vv. 2265-76)
\end{tabular}

\section{CONCLUSIONES}

La simplificación argumental y estructural llevada a cabo por Agustín Moreto en Cómo se vengan los nobles sintetiza la estructura dramática; esta tarea es acometida mediante una disminución de formas métricas, una simplificación de personajes, la eliminación de una segunda trama y una concentración espaciotemporal. Todo ello contribuye a que el enredo resulte más ameno y más fácil de seguir por parte del espectador, además de aumentar el suspense en algunos pasajes y concentrar la tensión dramática en la jornada final.

En la segunda mitad del siglo XVII, momento en el que Agustín Moreto compone Cómo se vengan los nobles, el parámetro que regía los designios creativos estaba basado en la imitatio, concepto clásico avanzado ya por Cicerón. El virtuosismo de los dramaturgos no estaba tanto en conseguir la creación de algo nuevo, sino en el hecho de, partiendo de unos mismos temas y argumentos, lograr una perfección más alta que la de su modelo, preparando la obra para espectadores con una estética distinta. De ahí que sea necesario analizar este tipo de reescrituras siendo conscientes de que el concepto de originalidad que manejamos actualmente, heredero del romanticismo alemán, difiere mucho del existente en el Siglo de Oro, ya que la tradición era para ellos un manantial de recursos, un océano de inspiración cuyo influjo podía ser perfectamente perceptible para el espectador del momento. De hecho, como apunta Francisco Aguilar Piñal, el proceso de refundir implicaba una valoración positiva de la obra que actúa como fuente, ya que se le presuponían toda una se- 
rie de cualidades y se le veía potencial para ser adaptada a un nuevo contexto sociocultural, el actual para los espectadores a los que iba a dirigirla (33). En este sentido, como en otras ocasiones, la principal virtud de Moreto fue la de analizar con esmero las características más destacadas de su modelo para, posteriormente, elaborar su refundición de la manera más eficiente posible. Siendo fiel al pragmatismo con el que entendía el espectáculo teatral, el dramaturgo madrileño suprime personajes accesorios o modifica la relación que se establece entre algunos de ellos; elimina acciones secundarias o intrascendentes para el desarrollo de la trama principal; reestructura algunas escenas y presenta una acción mucho menos dispersa. Además, actualiza alguno de los subtemas que palpitan en la historia y plantea perspectivas diferentes. No obstante, el cambio más profundo se produce, sin duda, con respecto a la caracterización del protagonista, que, sin dejar de ser el eje central en torno al cual se articula toda la comedia, no impide brillar al resto de sus compañeros de reparto. Moreto completa su personalidad a partir de las relaciones que teje con otros participantes dramáticos, siendo una de las más destacadas la que mantiene con Buscón, el gracioso, mucho más protagonista y presente en escena que en la obra lopesca. De hecho, en las fechas en que Lope concibe su obra este tipo de figuras no eran habituales, ya que la crítica apunta que el personaje del gracioso aparece por primera vez en la obra lopesca La francesilla, compuesta, según Morley y Bruerton (78), a finales del siglo XVI.

Esta apuesta de Moreto por la concisión, la claridad lingüística, la risa y la naturalidad dio sus frutos, no solo en un gran éxito en su época dentro y fuera de España, sino también en un interés actual por parte de la comunidad investigadora y los profesionales del teatro. Hoy en día, gracias, por ejemplo, a la labor del grupo Moretianos, encabezado por María Luisa Lobato, y a las puestas en escena de la compañía teatral Morboria Teatro y de la foven Compañia Nacional de Teatro Clásico, podemos seguir viendo cómo es capaz de despertar el aplauso del público en los diferentes escenarios en los que es representado.

\section{OBRAS CITADAS}

Aguilar Piñal, Francisco. "Las refundiciones en el siglo XVIII". Cuadernos de Teatro Clásico 5 (1990): 33-41.

Cayuela, Anne. "De reescritores y reescrituras: teoría y práctica de la reescritura en los paratextos del Siglo de Oro". Criticón 79 (2000): 37-46. 
Di Pinto, Elena. "El arte de la refundición según Moreto (I): El despertar a quien duerme, de Lope de Vega vs. La misma conciencia acusa, de Moreto". Compostella Aurea. Actas del VIII Congreso de la Asociación Internacional Siglo de Oro. Eds. Antonio Azaustre Galiana y Santiago Fernández Mosquera. Santiago de Compostela: Universidade de Santiago de Compostela, 2011. 107-14.

Diccionario biográfico de actores del teatro clásico español (DICAT). Recurso electrónico. Dir. Teresa Ferrer Valls. Kassel: Reichenberger, 2008.

Fernández de Avellaneda, Alonso. El Quijote apócrifo. Ed. Alfredo Rodríguez López-Vázquez. Madrid: Cátedra, 2011.

Fernández Mosquera, Santiago. "Reescritura en el Siglo de Oro: diferentes estrategias autoriales". El Siglo de Oro español: texto e imagen. Eds. Ignacio Arellano y Vsévolod Bagnó. Pamplona: EunSA, 2010. 23-37.

Genette, Gérard. Palimpsestos: la literatura en segundo grado. Trad. Celia Fernández Prieto. Madrid: Taurus, 1989.

Kennedy, Ruth Lee. The Dramatic Art of Moreto. Philadelphia: George Banta, 1932.

Kirby, Carol Bingham. "Hacia una definición precisa del término refundición en el teatro clásico español". Actas del x Congreso de la Asociación Internacional de Hispanistas. Ed. Antonio Vilanova. Vol. 2. Barcelona: PPU, 1992. 1005-11.

Lobato, María Luisa. "La dramaturgia de Moreto en su etapa de madurez (1655-1669)". Studia aurea: revista de literatura española y teoría literaria del Renacimiento y Siglo de Oro 4 (2010): 53-71.

López Martínez, Celestino. Teatros y comediantes sevillanos del siglo ХVI. Sevilla: Imprenta Provincial, 1940.

Menéndez Pelayo, Marcelino. Estudios sobre el teatro de Lope de Vega. Vol. 3. Ed. Adolfo Bonilla y San Martín. Madrid: Victoriano Suárez, 1922.

Moreto, Agustín. Cómo se vengan los nobles. Ed. Rafael Ramos. Disponible en www.moretianos.com. 9 de septiembre de 2018.

Morley, Sylvanus Griswold, y Courtney Bruerton. Cronología de las comedias de Lope de Vega. Trad. María Rosa Cartes. Madrid: Gredos, 1968.

Pérez Bowie, José Antonio. "Sobre reescritura y nociones conexas: un estado de la cuestión". Reescrituras filmicas: nuevos territorios de la adaptación. Coord. José Antonio Pérez Bowie. Salamanca: Universidad de Salamanca, 2010. 21-43.

Profeti, Maria Grazia. "Intertextualidad, paratextualidad, collage, interdiscursividad en el texto literario para el teatro del Siglo de Oro". La vil qui- 
mera de este monstruo cómico. Ed. Maria Grazia Profeti. Kassel: Università degli Studi di Verona/Edition Reichenberger, 1992. 107-18.

Rodríguez-Gallego, Fernando. "Aproximación a la reescritura de comedias de Calderón de la Barca”. Presencia de la tradición en la literatura española del Siglo de Oro. Ed. Natalia Fernández Rodríguez. Barcelona: Prolope/Universidad Autónoma de Barcelona, 2010. 157-93.

Ruano de la Haza, José María. "Las dos versiones de El mayor monstruo del mundo, de Calderón”. Criticón 72 (1998): 35-47.

Sáez Raposo, Francisco. "El equilibrio imposible del teatro de Agustín Moreto entre el plagio y el canon". Presencia de la tradición en la literatura española del Siglo de Oro. Ed. Natalia Fernández Rodríguez. Barcelona: Prolope/Universidad Autónoma de Barcelona, 2010. 195-225.

Segre, Cesare. "De Boccacio a Lope de Vega: derivaciones y transformaciones". Semiótica filológica. Texto y modelos culturales. Trad. José Muñoz Rivas. Murcia: Universidad de Murcia, 1990. 93-102.

Trambaioli, Marcella. "En el taller de la refundición de una comedia lopeveguesca: El Eneas de Dios o El caballero del Sacramento de Agustín Moreto". eHumanista 23 (2013): 258-81.

Ulla Lorenzo, Alejandra. "Sobre la reescritura de los finales en las comedias de Calderón: Polifemo y Circe (1630) y El mayor encanto, amor $(1635$ y 1668)". Compostella Aurea. Actas del VIII Congreso de la Asociación Internacional Siglo de Oro. Eds. Antonio Azaustre Galiana y Santiago Fernández Mosquera. Santiago de Compostela: Universidade de Santiago de Compostela, 2011. 485-96.

Vaccari, Debora. "Lope de Vega y la reescritura de la novela corta: el caso de Amar sin saber a quién". Novela corta y teatro en el Barroco español (16131685): studia in honorem prof. Anthony Close. Coords. Rafael Bonilla Cerezo y Begoña Rodríguez. Madrid: Sial, 2012. 87-105.

Vega, Lope de. El testimonio vengado. Ed. Gerardo Salvador Lipperheide. Comedias de Lope de Vega: parte 1. Vol. 3. Lleida: Milenio, 1997. 1687-805.

Vila Carneiro, Zaida. "Reutilización de material literario en las comedias de Calderón: un análisis desde sus piezas más tempranas". Rilce: Revista de Filología Hispánica 33.2 (2017): 726-47.

Vitse, Marc. "Presentación”. Criticón 72 (1998): 5-10. 